\title{
The Effect of Educational Interventions on Knowledge, Attitude and Practices of Mothers Regarding Febrile Convulsions in Children
}

\author{
Samina Kausar ${ }^{*}$, Saima Kouser, Zunaira Aziz, Farzana Bibi
}

University of Health Sciences, Lahore, Pakistan

DOI: $10.36348 /$ sjmps.2020.v06i07.006

| Received: 16.07.2020 | Accepted: 24.07.2020 | Published: 28.07.2020

*Corresponding author: Samina Kausar

\section{Abstract}

Febrile convulsion (FC) is one of the most common problems of children under five years of age. This fear provoking condition creates anxiety among parents particularly in mothers which may lead to mismanagement. The study aims to determine the impact of educational interventions on maternal knowledge, attitude \& practices regarding febrile convulsions before and after intervention. Study Design was Quasi-experimental (pre-posttest) and Setting was department of pediatrics, Jinnah hospital \& Children hospital Lahore. Methodology: 100 mothers having children with febrile convulsions were selected by using purposive sampling technique for the period May to October, 2019. On the first day pretest was conducted in which knowledge, attitude and practices on febrile convulsions was assessed. After pretest they were intervened with 01 week educational sessions, each session was of 01 hour. Posttest was conducted after 01 week. Data was collected by using a validated and reliable questionnaire before and after intervention. Analysis was done through statistical package for the social science (SPSS) version 20.0.Result: mean, \pm SD were given for quantitative variable while frequencies, percentages were given for qualitative variables. T-test was applied to compare pre $\&$ post effect of educational intervention on maternal knowledge, attitude \& practices of FC. P-value of $\leq 0.05$ was considered significant. The post-test results revealed a significant increase in mother's knowledge $(P=<0.002)$, attitude $(P=<0.01)$ and practice $(P=<0.04)$ of febrile convulsion. This study suggested that educational interventions worked efficiently in improving mother's knowledge, attitude and practice of FC.

Keywords: Attitude, Educational Intervention, Febrile Convulsion, Knowledge, Practice.

Copyright @ 2020: This is an open-access article distributed under the terms of the Creative Commons Attribution license which permits unrestricted use, distribution, and reproduction in any medium for non-commercial use (NonCommercial, or CC-BY-NC) provided the original author and source are credited.

\section{INTRODUCTION}

Febrile convulsion (FC) is one of the common child-hood problems. Children under five years of age are more vulnerable to such kind of convulsions. This condition creates fear and anxiety among parents particularly in mothers [1]. Febrile convulsion (FC) refers to a spasm that occurs most probably under the age of five years as a result of high body temperature with high incidence in the second year of life [2, 3]. Worldwide, $25-35 \%$ of the children are admitted in pediatric emergency units with fever and febrile convulsions [3-5]. Volta Regional Health Annual Reports 2014 also affirmed that febrile associated conditions contribute $30-40 \%$ of hospital admissions [6]. A small number of studies are conducted on the prevalence of FC in developing countries. A study conducted in Bangladesh, Jamaica and Pakistan under the objective to estimate the prevalence of childhood seizure reported that prevalence of febrile convulsions ranged from 10.9 to 62.8 per 1000 child population [7]. The findings of another study revealed that the prevalence of febrile convulsion in Asia is 3-9/1000 child population and in India is $5.59 / 1000$ population [8]. Looking into the contributing factors for febrile seizure, gender, positive family history and viral infections have been found most predominant [9]. Children are mostly presented with un-consciousness and uncontrollable trembling of arms and legs. Most febrile convulsions last only a few minutes $(<5$ minutes) and are appeared with fever above $101^{\circ} \mathrm{F}$ $\left(38.3^{\circ} \mathrm{C}\right)$. This condition is more frightening for parents especially for mothers, although, (FC) does not create any long-lasting health problems but is a fear provoking condition for the entire family.

So, families having children with history of febrile convulsions must be given sufficient information as the parents of children encountered with febrile convulsion are deficit in knowledge. They perceived it as epilepsy which is life threatening to their children and they were also unaware of the management of it at home [10]. Another study also documented that 
mothers had demonstrated poor knowledge, attitudes and practices about FC as some malpractices have been identified in this study which are potentially detrimental. These practices included forcing liquids by mouth, holding child's body forcefully to control convulsions, or placing object to keep the mouth open. So, the researchers emphasized the need of improvement in knowledge and behavior by increasing awareness among mothers through educational programs [11]. Similarly, the results of a study showed that despite having adequate knowledge about the causes and clinical manifestations of febrile convulsion; mothers are still stick with negative beliefs like supernatural forces cause convulsions. Such kinds of beliefs are well-versed of their decisions concerning management of febrile convulsion. There is a dire need for mothers to be equipped with accurate health information about the causes and appropriate home management of FC to reduce less than five mortality [12]. Likewise, a study identified that maternal inadequate knowledge, negative attitude and poor practices are the major predecessor in managing FC [13]. Findings of another study have also supported the importance of health education to alleviate maternal fear and concern and to promote appropriate fever management at home [14]. In addition, it is documented that parent's fear of fever and febrile convulsion is a main problem which may give rise to life threatening consequences so they must be equipped with appropriate education [15]. Moreover, a study conducted with an objective to assess the effect of teaching on knowledge, attitude and practices of mothers for prevention of febrile convulsion in children reported that educational interventions had significant effects on maternal knowledge, attitude and practices for managing FC as compare to those mothers who were not exposed to educational interventions [16]. Similarly, a pre-experimental one group pretest and posttest study also confirmed that the structured teaching program showed positive effects on maternal knowledge regarding management of febrile convulsion [17].

So, studies declared that improving maternal knowledge on management of febrile convulsion will help out to save the children from harm during febrile convulsion and will prevent children under five years of age from further complications.

Thus, improving maternal knowledge, attitudes and practices toward FC are essential. Therefore, an assessment of maternal knowledge, attitudes and practices to FCs is warranted for educating mothers. Numerous studies have explored the causes and natural history of febrile convulsions and have evaluated different management approaches but a small amount of data is accessible about maternal KAP. However, further research is needed among diverse cultures. A literature search did not reveal any study on this topic from Pakistan. Thus, it is the first study of its nature in Pakistan that aims at assessing maternal knowledge, attitude and practices whose children experienced febrile convulsions.

\section{Materials And Methods \\ Study Design: Quasi-experimental.}

Sampling Technique: Non probability purposive sampling technique was used.

Inclusion Criteria: Mothers having children less than five years of age with history of febrile convulsion were included in this study.

Exclusion Criteria: Mothers who have attended any workshop, seminar or teaching session on febrile convulsions awareness were excluded.

Study Setting: Department of Pediatrics Jinnah hospital \& Children Hospital Lahore.

Study Population: The study population comprised of mothers having children less than five years of age with history of febrile convulsion (Both first \& recurrent attack of FC).

Study Period: Six months from May, 2019-October, 2019.

Sample Size: One Hundred (100) mothers having children less than five years of age with history of febrile convulsion.

\section{Description of the Tool}

Self-administrated questionnaire was used for data collection. It was developed after critical review of the literature and discussion with professional experts and colleagues. This questionnaire consists of three parts, Part-1 demographic profile and Part-2 contains febrile convulsion related questions especially related to knowledge of causes, contributing factors, sign symptoms \& maternal attitudes and practices to manage FC in multiple choices \& Yes/No format and part three covers structured teaching module on febrile convulsion. The tool was translated into Urdu language for convenience of the participants.

\section{Validity and reliability of the research instrument} This tool was tested for content and face validity by experts. The questionnaire was given to different experts, for their feedback on content, set-up, and order. The validated questionnaire was then pilot tested. Ten mothers having children under five years of age who were not be a part of study sample was randomly selected and asked to complete the questionnaire. The purpose of pilot testing was to make sure that the respondents understand the questions or 
not. Reliability of the tool was computed by using Cronbach's alpha i.e. 0.80 .

\section{Data Collection Method}

After obtaining administrative permission from selected hospitals, the subjects were selected according to the inclusion and exclusion criteria by using purposive sampling technique. The study purpose was explained to the participants and written informed consent was obtained and questionnaire was disseminated to assess pre-test knowledge, attitude\& practices of FC. After pretest mothers were intervened with 01 week educational sessions, each session was of 01 hour. Posttest was conducted on $7^{\text {th }}$ day after educational intervention; the same questionnaire was given to the same group of mothers to assess educational intervention effects on maternal knowledge, attitude \& practices of FC.

\section{Statistical Analysis}

Analysis was done through statistical package for the social science (SPSS) version 20.0.To summarize the result mean, \pm SD (Standard Deviation) were given for quantitative variable like age while frequencies, percentage were given for qualitative variable like educational level, employment status etc. T-test was applied to compare pre \& post effect of educational intervention on maternal knowledge, attitude \& practices of FC. P-value of $\leq 0.05$ was considered significant.

\section{Ethical Considerations}

The researcher provided sufficient information about consent form and participants had the right to refuse or participate in the study and they can quit the study at any time. Consent form was signed by the participants. Adequate level of confidentiality of the participants and research data was maintained. It was assured to the respondents that their responses will only be used for research purpose.

\section{RESUlTS}

The major objective of current study was to determine the impact of educational intervention on maternal knowledge, attitude \& practices of febrile convulsions before and after intervention. So, this section provides the findings related to research objective. Student T-test was applied to measure the mean difference of before and after intervention.

Table-1: Frequency Distribution of subjects' Demographic characteristics

\begin{tabular}{|l|l|l|}
\hline Demographic Characteristics & Frequency (f) & Percentage (\%) \\
\hline Age groups & 55 & 54.7 \\
\hline$\bullet \quad 20-30$ & 45 & 43.5 \\
\hline$\bullet \quad 31-40$ & 54 & 53.8 \\
\hline Employment status & 26 & 25.7 \\
\hline$\quad$ Housewife & 20 & 19.8 \\
\hline$\bullet \quad$ Employee & 20 & 19.8 \\
\hline$\bullet \quad$ Professional & 18 & 17.6 \\
\hline Educational level & 45 & 44.7 \\
\hline$\bullet \quad$ Illiterate & 17 & 16.8 \\
\hline$\bullet \quad$ Primary school & Secondary level &
\end{tabular}

Table-1 represents subject's "Age, Employment status and Educational level. More than half of the mothers $(54.7 \%)$ presented with age group 20-30 years and $43.5 \%$ mothers fall between the age ranges of 31-40 years. In case of employment $53.8 \%$ mothers were house wives, $25.7 \%$ were employees and $19.8 \%$ were professional ladies. The educational level of mothers was categorized as illiterate, primary school, Secondary schooling and university i.e. $19.8,17.6 \%$, $44.7 \%$, and $16.8 \%$ respectively.

Table-2: Comparison of mean scores of study variables (knowledge, attitude \& practices).before and after intervention

\begin{tabular}{|l|l|l|l|l|l|l|}
\hline \multirow{2}{*}{ Variables } & \multicolumn{2}{|l|}{ Pre-intervention } & \multicolumn{2}{l|}{ Post-intervention } & Results of student T-test & \multirow{2}{*}{ P value } \\
\cline { 2 - 5 } & Mean & SD & Mean & SD & & \\
\hline Knowledge & 50.28 & 9.4 & 62.27 & 7.9 & 6.57 & $<0.002$ \\
\hline Attitude & 71.02 & 6.8 & 75.5 & 3.6 & 2.09 & $<0.01$ \\
\hline Practices & 68.09 & 5.9 & 78.17 & 4.69 & 2.01 & $<0.04$ \\
\hline
\end{tabular}

Table-2 reveals a significant increase in the mean scores of mother's knowledge with $\mathrm{p}$ value $<$ 0.002 , attitude $(\mathrm{p}=<0.01)$ and practices $(<0.04)$ after educational intervention regarding prevention of febrile convulsions in children as compared to before intervention. 


\section{DISCUSSION}

Febrile convulsion is not a serious condition as it has outstanding chances of prognosis but is highly associated with extreme apprehension and anxiety of parents. Misconceptions and mismanagement put the child life at threat. About 2-5\% of the children under the age of five years who are even strong neurologically and cognitively experience febrile seizure at least 1 episode in their life [18]. So, appropriate management at onset is mandatory.

In order to realize study objective t- test was applied to compare pre \& post effect of educational intervention on maternal knowledge, attitude \& practices of FC. The findings revealed significant difference in mean score of pre and post intervention as before educational sessions, mean score of mother's knowledge was found at moderate level and after intervention a significant increase was observed in mother's knowledge. The results of current study regarding mother's knowledge found to be in line with the findings of randomized control trails studies documenting that there was a significant increase in maternal knowledge of FC after educational sessions $[19,20]$. However, before intervention attitudes of mothers was found comparatively better than knowledge and it was also improved after intervention of educational sessions. Our findings are comparable with two other studies that educational sessions with parents played a significant role in decreasing parents' anxiety and increasing their understanding of management of febrile convulsion in children [21, 22]. As for maternal practice about management of FC, it was also improved as maternal misconceptions of managing FC were clear after educational sessions. These findings are similar to two other studies reporting that standard practices of managing FC were observed after teaching session with mothers on FC [22, 23].

It is evident that the educational sessions are effective means of improving maternal understanding, attitude and practices of FC which can consequently be helpful in enhancing confidence and internal serenity of mothers leading to appropriate action and timely management.

\section{Conclusion}

Educational interventions are a key step to lessening parenteral apprehensions and increasing parents' knowledge in treating fever and febrile illness in their children. So, parents should be equipped with all the necessary information regarding management of febrile illness either through a vast media campaign by qualified health professionals or by community-based educational sessions.

Disclaimer: None.

Conflict of Interest: None.
Source of Funding: None.

\section{REFERENCES}

1. Parmar, R. C., Sahu, D. R., \& Bavdekar, S. B. (2001). Knowledge, attitude and practices of parents of children with febrile convulsion. Journal of postgraduate medicine, 47(1), 19.

2. Seinfeld, D. S., \& Pellock, J. M. (2013). Recent research on febrile seizures: a review. Journal of neurology \& neurophysiology, 4(165).

3. Jarrett, O. O., Fatunde, O. J., Osinusi, K., \& Lagunju, L. A. (2012). Pre-hospital management of febrile seizures in children seen at the university college hospital, Ibadan, Nigeria. Annals of Ibadan postgraduate medicine, 10(2), 6-10.

4. Delpisheh, A., Veisani, Y., Sayehmiri, K., \& Fayyazi, A. (2014). Febrile seizures: etiology, prevalence, and geographical variation. Iran $J$ Child Neurol. 8:30.

5. Graneto, W. J. (2011). Emergent management of paediatric patients with fever. Available: https://emedicine.medscape.com/article/801598overview.

6. https://www.ghanahealthservice.org/downloads/G hana_Health_Service_2014_Annual_Report.pdf

7. Durkin, M. S., Davidson, L. L., Hasan, Z. M., Hasan, Z., Hauser, W. A., Khan, N., ... \& Zaman, S. (1992). Estimates of the prevalence of childhood seizure disorders in communities where professional resources are scarce: results from Bangladesh, Jamaica and Pakistan. Paediatric and perinatal epidemiology, 6(2), 166-180.

8. Vadani, V. (2005). Pediatric febrile convulsion-An Indian perspective. Indian J Pediatr, 35:55-59.

9. Gourabi, H. E., Bidabadi, E., Cheraghalipour, F., Aarabi, Y., \& Salamat, F. (2012). Febrile seizure: demographic features and causative factors. Iranian journal of child neurology, 6(4), 33.

10. Kayserili, E., Ünalp, A., Apa, H., Asilsoy, S., Hizarcioğlu, M., Gülez, P., \& Agin, H. (2008). Parental knowledge and practices regarding febrile convulsions in Turkish children. Turkish Journal of Medical Sciences, 38(4), 343-350.

11. Asiri, N. A., Joubah, M. A. B., Khan, S. M., \& Jan, M. M. (2015). Maternal knowledge of acute seizures. Neurosciences, 20(4), 346.

12. Nyaledzigbor, M., Adatara, P., Kuug, A., \& Abotsi, D. (2016). Mothers' knowledge beliefs and practices regarding febrile convulsions and home management: A study in Ho Ghana. Journal of Research in Nursing and Midwifery, 5(2), 3036.

13. Anigilaje, E. A., \& Anigilaje, O. O. (2012). Childhood convulsion: inquiry about the concerns and home management among mothers in Tegbesun, a Periurban Community in Ilorin, 
Nigeria. International Scholarly Research Notices, 2012.

14. Al-Nouri, L., \& Basheer, K. (2005). Mothers' perceptions of fever in children. Journal of tropical pediatrics, 52(2), 113-116.

15. Bavdekar, S., Ghule, R., \& Jadhav, S. (2008). Healthcare-seeking behavior after seizures in children. Indian journal of medical sciences, 62(8), 331-335.

16. Najimi, A., Dolatabadi, N. K., Esmaeili, A. A., \& Sharifirad, G. R. (2013). The effect of educational program on knowledge, attitude and practice of mothers regarding prevention of febrile seizure in children. Journal of education and health promotion, 2.

17. Joseph, J., \& George, J. (2015). Structured teaching programme regarding knowledge and management of febrile seizure among mothers of under five children. IJSR, 5:1070-74.

18. Kliegman, R. M., Stanton, B., Geme, J., \& Schor, N. F. (2016). Nelson textbook of Pediatrics, 20th edition, Elsevier. 593:4302.

19. Parbi, H., \& Neamatolahi, A. Evaluation knowledge of parents of children with febrile convulsion. Medical university of khoramabad, shahid madani hospital. Iranian Pediatric Journal, 1382(26), 10-18.

20. Kelly, M., Sahm, L., McCarthy, S., O’Sullivan, R., Mc Gillicuddy, A., \& Shiely, F. (2019). Randomised controlled trial of an intervention to improve parental knowledge and management practices of fever. BMC pediatrics, 19(1), 1-10.

21. Barzegar, M., Valizadeh, S., Gojazadeh, M., Jafarabadi, M. A., Zamanzadeh, V., \& Shahbazi, S. (2016). The effects of two educational strategies on knowledge, attitude, concerns, and practices of mothers with febrile convulsive children. Thrita, 5(2), e3341.

22. Elbilgahy, A. A., \& Abd El Aziz, R. A. E. (2018). Effect of implementing an educational module on improving mothers' knowledge, home management and attitude about febrile convulsion. Journal of Nursing Education and Practice, 8(3), 1-11.

23. Henderson, D. P., Thomas, D. O., Murphy, K. A., \& Liebman, M. (1995). Fever care: Does nursing instruction make a difference?. Journal of Emergency Nursing, 21(5), 461-463. 